\title{
Effects of temperature on High Concentration Erbium-doped fiber intrinsic parameters
}

\author{
Francisco J. Madruga*, M. Ángeles Quintela, Carlos Galíndez, Mauro Lomer, José M. López- \\ Higuera \\ Photonic Engineering Group, University of Cantabria, ETSIIT, Santander Spain.
}

\begin{abstract}
The effects of temperature on High concentration Erbium-doped fibers are characterized using parameters of transcendental equation model. The intrinsic parameters (intrinsic saturation power, excited-state lifetime and linear absorption coefficient) of six Erbium doped and Erbium codoped with Lanthanum fibers have been measured for different temperatures. The temperature dependence of intrinsic parameter has been compared respect to Erbium concentration and Lanthanum-Erbium concentration ratio.
\end{abstract}

Keywords: Erbium doped fiber, temperature, high concentration, lanthanum codoped, intrinsic parameter.

\section{INTRODUCTION}

Erbium doped fiber amplifiers (EDFA) are commonly used in telecommunications systems. EDFA has many advantages such as high gain, low noise-figure, low loss insertion polarization-insensitive [1]. Currently, efficient amplifier operation requires low Erbium-doped concentration fibers and then several meters of Erbium-doped fiber (EDF) are used. In order to reduced the amplifier size, high concentration The performance of EDFA with erbium ion concentration as high as $8900 \mathrm{ppm}$ and an aluminum concentration of $8000 \mathrm{ppm}$ has been reported [2]. It decreases due to concentration quenching. The quantum conversion efficiency of $28 \%$ has been reported for fibers, which concentration of $5900 \mathrm{ppm}$ [3]. Erbium codoped with Lanthanum species techniques are used, in order to decrease the pair induced quenching, to increase the conversion efficiency and to obtain a flattening effect of the gain profile.

Recently, in order to reduce the fiber length for L-band amplifier an Erbium-Lanthanum codoped fiber amplifier has been presented [4]. Its applications to WDM systems could be limited by the temperature dependence of the Er-La fibers.

In this letter, the temperature dependence of five highly Er-doped and Er-La codoped fiber parameters ( $\alpha_{k}$, absorption coefficient and $\mathrm{P}_{\mathrm{k}}$, intrinsic saturation power) are reported. The determination of amplifier gain can be deduced from the solutions of $\mathrm{N}$ differential equations to the solution of following single transcendental equation [5]

$$
P_{\text {out }}=\sum_{K=1}^{N} A_{k} e^{-B_{k} P_{\text {out }}} ; \quad A_{K}=P_{k}^{I N} e^{-\alpha_{k} L} e^{P_{\text {in }} / P_{K}^{I S}} ; \quad B_{k}=1 / P_{k}^{I S}
$$

The fiber properties have been replaced by two parameters, which can be easily determined from the fiber measurement. If $\alpha_{\mathrm{k}}$ and $\mathrm{P}_{\mathrm{k}}{ }_{\mathrm{IS}}$ are known, $\mathrm{P}_{\text {out }}$ can hence be calculated. The temperature dependence of this parameter can be approximated by[6]

$$
\alpha(\lambda, T)=\alpha(\lambda, \infty) \cdot e^{\beta(\lambda) / K \cdot T}
$$

where $\alpha(\lambda, \infty)$ and $\beta(\lambda)$ are function defined from two spectra at different temperature. $\alpha(\lambda, \infty)$ is temperature independent and is interpreted as the absorption when all energy levels are equally occupied. That is according to Boltzmann statistics at infinite temperature. $\beta(\lambda)$ is used to model the thermal occupation probability of the initial energy level for transition at a given wavelength.

\footnotetext{
*Madruga@teisa.unican.es; phone 34942 200879; fax 34942 200877; grupos.unican.es/gif

Third European Workshop on Optical Fibre Sensors, Antonello Cutolo, Brian Culshaw, José Miguel López-Higuera, Eds., Proceedings of SPIE Vol. 6619, 66190W, (2007) $\cdot 0277-786 X / 07 / \$ 18 \cdot$ doi: 10.1117/12.738365
} 


\section{EXPERIMENTAL WORKS}

Six types of Erbium doped fibers were fabricated using Modified Chemical Vapor Deposition (MCVD) and solution doping techniques. Their basic specifications are listed in table I. These fibers have been fabricated with different Erbium-doped concentration, host composition controlling the pulling temperature and speed. The cores of fiber 3,4,5,6 were codoped with Lanthanum and Aluminum. 243

The temperature dependent intrinsic parameters of fibers were made using a configuration with two optical sources. A white light source based in halogen lamp and a HP8168 tunable laser source for the $1500 \mathrm{~nm}$ band. Through a lightwave switch (HP 86061C) the light from the sources, were launched into the EDF under test as it is shown in Fig 1.

According to this set up, both the absorption spectrum and the flat top pulse from the EDF's were monitored using other same lightwave switch with an Optical Spectrum Analyzer Anritsu MW9002 and a digital oscilloscope through an optical-electric converter (OEC). Fibers were placed inside of a climatic chamber Hygros 15. All process was controlled by PC through GPIB and RS232 interfaces.

In order to obtain the temperature-dependent parameters, the climatic chamber temperature was changed from 0 to $60^{\circ} \mathrm{C}$ with step of $5^{\circ} \mathrm{C}$ and from 60 to $0^{\circ} \mathrm{C}$. Using a fast, single and non-destructive method described by Mazzali and col.[7], the intrinsic saturation power and linear absorption coefficient have been measured. In addition, the excited state lifetime was measured too.In order to compare the result, a low Er-doped concentration fiber (fiber 7) and a standard telecommunication fiber were used. Fiber lengths were chosen to equalize the total loss, excluding standard fiber.


Fig. 1. a) General experimental configuration for measurement of EDF intrinsic parameters. b) Detail of the different configuration for the measurement of different parameter.

TABLE I

CHARACTERISTIC OF MEASURED ERBIUM DOPED FIBERS

\begin{tabular}{ccccc}
\hline \hline Fiber & Ratio La/Er & $\begin{array}{c}\text { Absorption peak } \\
\mathrm{dB} / \mathrm{m}\end{array}$ & $\begin{array}{c}\text { Core diameter } \\
\mu \mathrm{m}\end{array}$ & $\begin{array}{c}\text { Cutoff wavelength } \\
\mu \mathrm{m}\end{array}$ \\
\hline Fiber 1 (Er) & 0 & 100 & 3.83 & 1,07 \\
Fiber 2 (Er) & 0 & 100 & 3.83 & 1,07 \\
Fiber 3 (Er-La) & 1 & 144 & 3.83 & 1,13 \\
Fiber 4 (Er-La) & 1 & 146 & 3.83 & 1,125 \\
Fiber 5 (Er-La) & 3.5 & 99 & 7.29 & 1,02 \\
Fiber 6 (Er-La) & 3.5 & 90 & 7.29 & 1,02 \\
Fiber 7 (reference) & 0 & 5 & 7.29 & 1,1025
\end{tabular}




\section{RESULTS AND DISCUSSION}

In order to obtain similar light power on both detectors (OSA and OEC), fiber lengths were selected to reach similar absorption loss. The temperature dependence trends of absorption coefficients of fibers have been studied from the evolution of $\beta$-function (equation 2) shown in the figure 2. A change of sign is observed in function $\beta$ at wavelengths around $1540 \mathrm{~nm}$. That is, the temperature coefficient of absorption of optical fiber (C.T. $\alpha$.) That is, a value of wavelength for which the coefficient of temperature of absorption is null, is defined.

As shown in Fig 3, saturation intrinsic power $\left(\mathrm{P}^{\mathrm{IS}}\right)$ grows with temperature at wavelength of $1536 \mathrm{~nm}$. At this wavelength, the maximum variation of $\mathrm{P}^{\mathrm{IS}}$ has been measured. Shift of wavelength value to

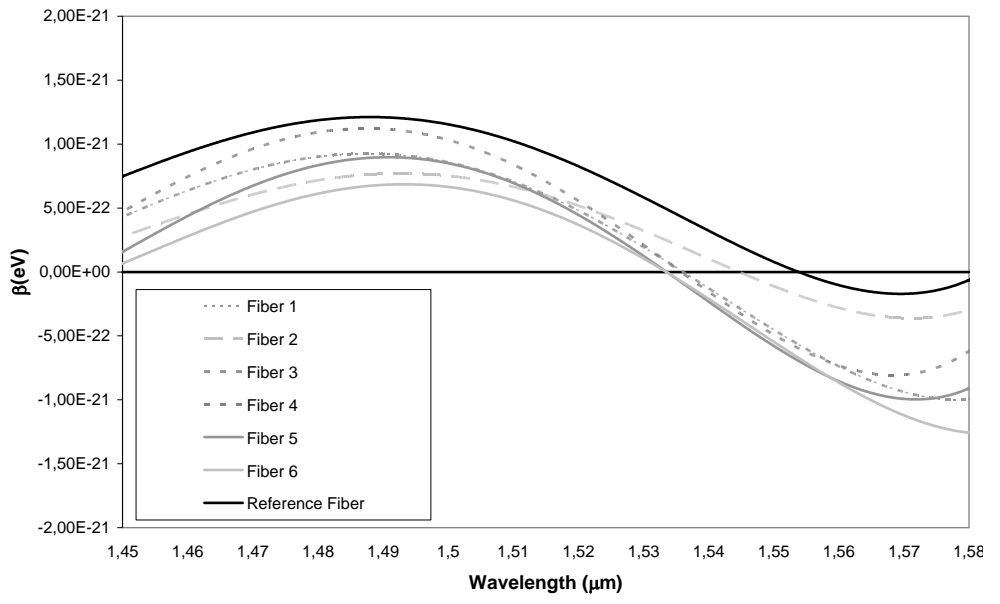

Fig. 2 Function $B$ obtained from absorption coefficient measurements.

higher one is observed with the La/Er concentration ratio (fiber 5 and 6). At $1480 \mathrm{~nm}$ (pump source), the $\mathrm{P}^{\mathrm{IS}}$ temperaturedependent is neglected. This can be approach linearly through the trend line. Writing $\mathrm{P}^{\mathrm{IS}}=\mathrm{A}+\mathrm{BT}$, where $\mathrm{A}$ and $\mathrm{B}$ are constant obtained from the trend line of data in Fig 3. La-ion presence changes A and B values. The Er-doped concentration fiber keeps practically the same behavior with temperature. When the fiber contains La-ions the behavior with temperature was not influenced the pulling conditions, but the $\mathrm{P}^{\mathrm{IS}}$ values do. That is, La-doped fiber fabrication conditions changes A-value. Moreover, when the $\mathrm{La} / \mathrm{Er}$ concentration ratio increase, the $\mathrm{B}$ value decreases, that is, temperature-dependent is reduced. In order to quantify the temperature-dependent, Intrinsic Saturation power temperature coefficient $\left(P^{I S} T C\right)$ has been defined as

$$
P^{I S} T C=\frac{1}{P^{I S}} \cdot \frac{\partial P^{I S}}{\partial T}
$$

where $\mathrm{P}^{\mathrm{IS}}{ }_{0}$ is the intrinsic saturation power at $25^{\circ} \mathrm{C}$ (ambient temperature). The $P^{I S} T C$ value of $0.009{ }^{\circ} \mathrm{C}^{-1}$ for fibers which $\mathrm{La} / \mathrm{Er}$ ratio is 3.5 and of $0.018 \mathrm{C}^{-1}$ for fibers without La-ions inside theirs cores. The table II shows the $P^{I S} T C$ values for all fibers used in the experiment for temperature changes from 0 to $60^{\circ} \mathrm{C}$ and from 60 to $0^{\circ} \mathrm{C}$. Non-hysteresis effect has

\begin{tabular}{ccc}
\multicolumn{3}{c}{ TABLE II } \\
\multicolumn{3}{c}{$P^{I S}$ TC VALUES } \\
\hline \hline Fiber & $0-60$ & $60-0$ \\
& $\mathrm{~A}$ & $\mathrm{~A}$ \\
\hline Fiber 1 (Er) & 0.0184 & 0.0177 \\
Fiber 2 (Er) & 0.0189 & 0.0184 \\
Fiber 3 (Er-La) & 0.0151 & 0.0141 \\
Fiber 4 (Er-La) & 0.0146 & 0.0142 \\
Fiber 5 (Er-La) & 0.0115 & 0.0106 \\
Fiber 6 (Er-La) & 0.0098 & 0.0087
\end{tabular}



Fig. 3. The measured dependence of Saturation Intrinsic Power PIS on temperature for six different fibers at wavelength of $1536 \mathrm{~nm}$. and the trend line of Saturation Intrinsic Power PIS on temperature. 
been observed.

Finally, temperature-dependent of the excited state lifetime has been measured as it is showing on Fig 4. Note that we don't need it to calculate the EDFA gain using the model [5]. The slope of temperature-dependent of the excited state lifetime was practically the same, for all fiber prove. La-ions in host did not affect it, but they reduced the excited state lifetime.

\section{CONCLUSIONS}

The temperature-dependent of intrinsic saturation power, excitedstate lifetime and linear absorption coefficient of several doped and



Fig. 4. Measured dependence of excited state lifetime on temperature different fibers at wavelength of $1536 \mathrm{~nm}$.

codoped fiber have been experimentally investigated. Its dependence decreases in higher Erbium concentration fiber. Er-La codoped fibers show lower temperature dependent with the $\mathrm{La} / \mathrm{Er}$ concentration ratio. The absorption temperature coefficient presents a zero value at the wavelength range 1530-1550. And his contribution to the temperature dependence is minimal. Intrinsic saturation power increases with temperature, but excite state lifetime decreases.

As final conclusion, the temperature dependence reported in this letter, suggests that La-concentration increasing in Er-La codoped fiber improves the stable operation of fiber amplifier when the operation temperature changes.

\section{ACKNOLEDGMENTS}

The fibers were fabricated at BT lab during Prof. Lopez Higuera's stay. Doug Williams is thanked for his invaluable help. Finally the authors wish to thank David Millán for his collaboration during the characterization works in the R\&D Photonic engineering Laboratory of University of Cantabria

\section{REFERENCES}

1. Anders Bjarklev, "Optical Fiber amplifiers: Design and system applications”, Ed.Boston: Artech House, 1993.

2. Y. Kimura, M. Nakazawa. "Gain Characteristic of Erbium doped fibre amplifiers with High Erbium Concentration", Electronics letters V28, No15, 1992.

3. Piort Myslinski, Czeslaw Szubert, Allan J. Bruce, David DiGiovanni, Bera Palsdottir, "Performance of High concentration Erbium-doped fiber amplifiers", IEEE Photon. Technol. Lett. V11, Nº, 1999.

4. Keiichi Aiso, Yoshio Tashiro, Tsuneo Suzuki and Takeshi Yagi "Erbium Lanthanum co-doped fiber for L-band amplifier with high efficiency low non linearity and low NF" OFC 2001

5. A. A. M. Saleh, R. M. Jopson, J.D. Evankow, J. Aspell. "Modeling of Gain in Erbium doped fiber amplifiers", IEEE Photon. Technol. Lett. V2, No10, 1990.

6. M. Bolshtyansky, Paul Wysocki, Nicholas Conti. " Model of temperature dependence for gain shape of Erbium doped fiber amplifier", JLT V18, $\mathrm{n}^{\circ} 11,2000$.

7. C. Mazzali, H.L. Fragnito, E. Palance, D.C. Dini. "Fast method for obtaining Erbium doped fibre intrinsic parameters" Electronics Letters V32 nº10, 1996. 